\title{
Orientation and Content of Communication of Contemporary Youth
}

\author{
Margarita Nabiullina ${ }^{1, *}$, and Irina Cheremisova ${ }^{2}$ \\ ${ }^{1}$ P.G, Volgograd State University, 400062, Volgograd, Universitetsky Ave., 100, Russia \\ ${ }^{2}$ EDP Sciences, Volgograd State University, 400062, Volgograd, Universitetsky Ave., 100, Russia
}

\begin{abstract}
The article is devoted to the study of the peculiarities of communication between youngsters and their peers and parents. Based on the comparative analysis, typical and variable formal-content characteristics of communication were determined. Among boys and girls, the manipulative and altrocentric orientations in communication is equally common. Dialogue as a form of communication is poorly indicated in both groups. Girls are less inclined towards dialogue than young males. Young people, regardless of sex, are more tending to communicate with their peers than with their parents. Girls often turn to their parents for advice and share their secrets with them. Boys discuss work, hobbies and plans for the future with their parents. When communicating with peers, young men are prone to authoritarianism, and girls are less assertive.
\end{abstract}

Communication is one of the main conditions and ways of existence and development of a person. For young men and women, communication with adults as a learning activity is one of the basic needs during adolescence.

The growing need for communication with adults is conditioned by youngters' desire for acceptance, recognition and a need to feel confident. It is necessary for problem solving during adolescence, and validation can only be received through communication with others.

Communication between people has different forms and directions. The dialogical form of communication allows for a more constructive and detailed discussion as well as development of problem-solving skills. M.M. Bakhtin in his work notes, "One person, who remains only with himself, can not make ends meet even in the most profound and intimate spheres of his spiritual life, can not do without another consciousness. Man will never find fullness only in himself "[1].

T.A. Topolskaya distinguishes six basic ways of understanding of the concept of "dialogue" in psychological studies of communication and psychological practice: dialogue as a form of speech interaction; dialogue as a joint thought process; dialogue as a joint activity of interlocutors in overcoming contradictions between them; dialogue as communication at the level of actual motives of activity; dialogue as communication based on the personal nature of the relationship; dialogue as an existential event [2].

The category "dialogue" has a multitude of meanings, and authors use those meanings with various goals. It is used in an extremely narrow meaning (for example, as a certain moment of communication), in a broad sense (the whole person's life is a dialogue), as an explanatory principle, and "how" phenomenon.

M.M. Bakhtin, A.F. Kopyev, A.B. Orlov, T.A. Florenskaya, A.U. Kharash viewed dialogue as an informational phenomenon, a cognitive process, a movement towards cooperation, an open communication channel, and as a communication based on humane values.

Yu.S. Pezhemskaya defined the concept of continuous dialogue as a system of relationships that allows for problem-solving. Parent and a child in a dialogue format become co-researchers in this process [4].

Following the idea of dialogical consciousness of $\mathrm{M}$. Bakhtin, A.F. Kopyev and Yu.S. Pezhemskaya develop a notion of dialogue as an event of communication. Dialogue in Bakhtin's theory is interpreted as an education where self-development is based on a contradiction between the main constituents of dialogue - Self and the Other [5,6]

Defining ontology of dialogue as a space of meaning, L.I. Vorobyova believes that in a dialogue there is always an external factor that takes place in an existential space. Meaning that dialogue occurs in a situation where the sense of existence of the subject at a given moment of life must be achieved [7].

In communication, interests are defined, as well as ideas about oneself and the surrounding world are formed. During adolescence, young people actively establish contacts, and interpersonal interactions with other people.

A number of studies have revealed that direct contact is the most comfortable for a majority of people, regardless of age. At the same time, the progress of communication technologies in modern society, connected with alternative sources of communication, profoundly affects the communication of young people.

The frequency of using virtual communication channels is increasing, communication becomes superficial, more formal, the sincerity and intimacy between the interlocutors are lost, the emotional wholeness disappears, as well as an opportunity to look 
interlocutor in the eye and to respond to their facial expressions is diminished, and, finally, the level of speech culture and the value of communication itself is reduced. $[8,9,10]$

The need for direct communication is obstructed. The younger generation increasingly seeks to satisfy their needs in a positive evaluation, in their attention to themselves, in their awareness of belonging to a group in virtual communication $[11,12]$. This undoubtedly complicates the process of full-fledged development of the maturing personality.

According to the studies of I. Kohn, young men and women are characterized by a higher differentiation of emotional responses and ways of expressing emotional states, as compared to adults, and also by increased selfcontrol and self-regulation. Youthful moods are much more stable and conscious, and correspond with a much wider range of social conditions. [13]

The process of discovering a personal "Self" is complex and internally debatable. Suddenly it is revealed that the inner "Self" does not coincide with external behavior, thus the problem of self-control manifests. Uncertainty, insufficient differentiation of one's "Self" at this age causes anxiety, inner emptiness what in turn generates an increased need for communication and simultaneously increases its selectivity. [13]

In modern studies, scientists describe that the process of growing lengthens. Young people continue to feel the need to support their parents, not only financially, but also psychologically. They continue to experiment with their adulthood, searching for their identity and their place in the adult world. [14,15]

This allowed us to assume that communication with parents continues to be an urgent need for young people. Therefore, the following study was conducted to support the claim above.

The study involved students enrolled in various institutions of higher education in the number of 60 people aged 18-23 years (30 boys and 30 girls).

The purpose of our study was to identify the formally meaningful characteristics of the communication of the current young generation. It was important to study the value-semantic aspects of communication between young men and women with other people. Therefore, the method of "The direction of personality in communication" was used.

S.L. Bratchenko understands the direction of communication as a set of conscious personal semantic attitudes and value orientations in interpersonal communication. This technique allows us to identify the value-semantic relationships of the individual in the sphere of communication with other people, to reveal the degree of manifestation of the types of personal orientation, as well as the dominant type of orientation in communication and the ratio of the degree of expression of other orientations. The author of the method identifies six types of orientation in communication: dialogical, authoritarian, manipulative, altero-centrist, conformal and indifferent. [16]

The results are shown in fig. 1 (in the group of girls) and fig. 2 (in the group of young men).
The figure shows that for $33 \%$ of girls communication is characterized by a manipulative focus in communication, which means the orientation on the use of communication, taking into account only their goals, is to receive various kinds of benefits for themselves and their attitude towards the partner as the object of their manipulations. In communication they are isolated and insincere.

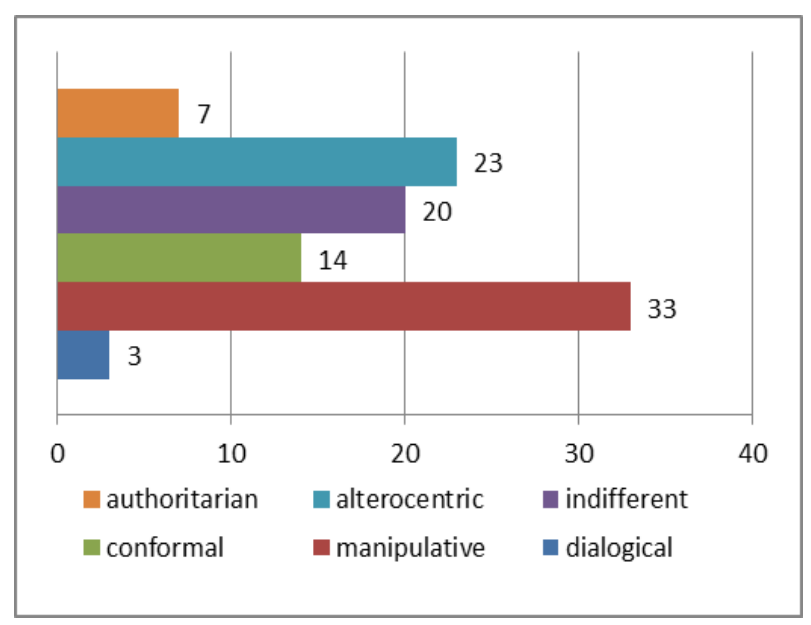

Fig 1. Orientation in communication of girls, $\%$.

Alterocentric orientation in communication is manifested in $23 \%$ of girls. They are concentrated on the interlocutor and are guided by their purposes, needs, and ready to sacrifice their own interests, aspire to satisfy others.

$20 \%$ of girls are dominated by the indifference of personality in communication. We can say that in this case, the situation of communication, goals and interests as an interlocutor and their own are ignored. According to S.L. Bratchenko this orientation indicates a hidden authoritarian attitude towards the interlocutor, in such situation, communication with him depreciates or ceases. [16]

For $14 \%$ of girls, the predominant is the conformal orientation. They occupy a passive position in communication, do not seek a deep understanding of the partner, and they do not demonstrate any desire to be understood. They are ready to change their opinion under the influence of circumstances or someone else's point of view, are prone to submission.

Authoritarian type of personality orientation in communication was revealed in $7 \%$. These girls show egocentrism, are inclined to show intolerance towards others and disrespect for someone else's point of view, they try to subordinate the interlocutor in different ways.

Dialogic orientation in communication occupies the last place in the percentage content among the other types of personality orientation and makes up only $3 \%$ in the group of girls. Meaning that a very small number of girls are eager for dialogue, mutual understanding and cooperation with the interlocutor.

In the group of young males, the orientation of the person to manipulative communication was found in $30 \%$ of the subjects, that is, every third tries to use the partner to achieve their goals. They try to understand 
their interlocutor as much as possible in order to obtain the necessary information and on its basis to covertly control his behavior.

For $23 \%$ of boys, the altrocentric trend is characteristic. This indicates the orientation towards the goals and needs of the partner, an indifferent attitude to how their partner understands and perceives communication.

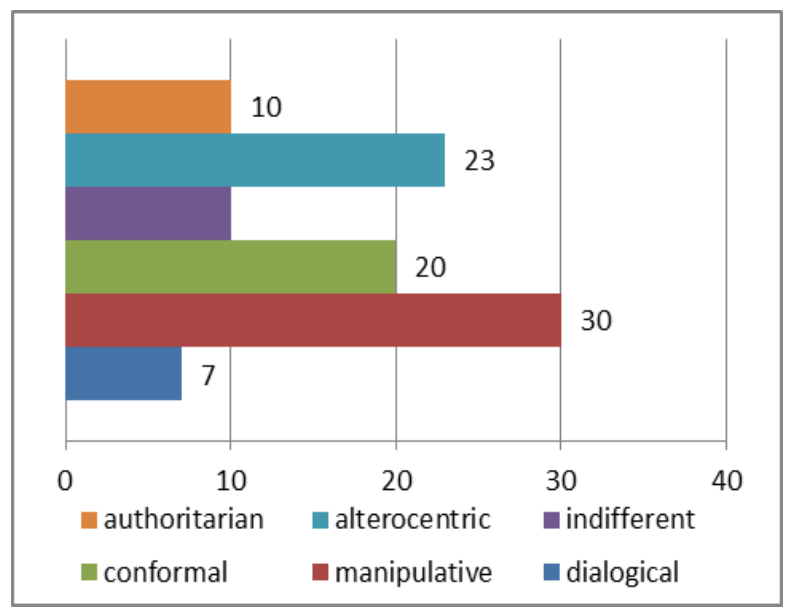

Fig 2. Orientation in communication of young men, $\%$.

$20 \%$ of young men have an indifferent attitude in communication, which is characterized by an indifferent attitude to both the interlocutor and the very process of communication. In behavior, this can be manifested as avoiding communication or reducing it to purely formal aspects.

In this group of young people, an authoritarian type of personality orientation in communication was revealed in $10 \%$. This indicates that the young men are more focused on dominance in communication, the desire to suppress the personality of the interlocutor, to control them.

Conformal orientation in communication is dominant to $10 \%$ of young men. This orientation presupposes an incline towards subordination of the authority to authority, the lack of desire for real understanding and the desire to be understood, the imitation and readiness to adapt to the interlocutor. $7 \%$ of young men show a dialogical orientation in communication.

Based on the information above, we will now analyze the survey's results. Both boys and girls are very poorly oriented towards equal, ethical interpersonal communication based on mutual trust, respect and cooperation. Every fifth subject, regardless of gender, sees no sense in communicating with another and tries to avoid it. For each third, the meaning of communication is the manipulation of the other. They behave insincerely, demonstrate a one-sided orientation to themselves at the expense of another. Approximately one in four demonstrates the altrocentric orientation, focusing on the partner and his interests, seeking to promote the development of the other to the detriment of their own development.

These three types of communication dominate both boys and girls. As for the differences, young males are more inclined towards the authoritarian nature of the person's orientation in communication. Girls often display a refusal of equality in communication in favor of the interlocutor, which means a conformal orientation in communication.

To analyze the content characteristics of communication between boys and girls, the survey method was used. The purpose of the questionnaire is to compare the content of communication between young men and women with their parents.

Research questions helped clarify the following aspects:

1. What is the duration of communication between young men and women with their parents?

2. What is discussed when communicating with parents?

3. What feelings do young men and women experience in a situation of communication with their parents?

4. What is the position of the interlocutors in communication?

The questionnaire consisted of multiple-choice options and the self-developed detailed answers to open questions. Analysis of answers to open-ended questions was carried out with the help of content analysis.

The analysis of respondents' answers showed the following. In the group of young men, the duration of communication with parents in $57 \%$ does not exceed one hour per day. This is clearly not enough for a full-fledged confidential communication between children and their parents.

One to three hours of communication lasts for $17 \%$ of young men, and $27 \%$ communicate with their parents for more than three hours every day. In the group of girls results are more evenly distributed: $33 \%$ of girls do not communicate with their parents for more than one hour a day, $37 \%$ - from one to three hours, and $30 \%$ communicate with their parents for more than three hours a day. It turns out that only one third of respondents have enough time to communicate with their parents. In total, $70 \%$ of girls communicate with their parents for more than one hour a day, but only $44 \%$ of boys do the same.

We also found out which of the parents are most often contacted by the respondents. It turned out that more than half of the respondents ( $60 \%$ of boys and $77 \%$ of girls) often communicate with their mother. In this case, girls do it more often. $10 \%$ of boys more often communicate with the father, but among the girls there are no examples of dominant paternal communication. $30 \%$ of boys and $23 \%$ of girls communicate with both parents an equal amount of time.

At the same time, $27 \%$ of boys and $33 \%$ of girls would like to spend more time with their parents. Apparently this is due to the fact that there are a number of issues that they would like to discuss not with peers, but with parents. It was found that girls are more likely to seek advice from their parents (73\%) than boys (37\%). Only $30 \%$ of girls and $20 \%$ of boys share secrets with their parents. Parents also seek advice for their adult children, while their daughters are asked for advice more often $(57 \%)$ than their sons $(27 \%)$. This indicates a 
greater parental confidence in communicating with daughters.

Analyzing what respondents usually communicate with their parents about, we found that $20 \%$ of respondents find it difficult to identify specific topics and answered that they are talking about "different things." This may mean the absence of common topics for discussion between children and parents, as well as the distance in the relationship. $24 \%$ of young men and $25 \%$ of girls talk about their studies with their parents.

This concludes the similarity in the answers of the respondents. The remaining answers were as follows: $15 \%$ of young men talk to their parents about work, $12 \%$ - tell their parents about themselves. In the sample of girls, $12 \%$ noted that they communicate with their parents on everyday issues, about love and about themselves. The smallest percentage of respondents talk with their parents about the future and about choosing a profession.

We found out that $38 \%$ of young men and $20 \%$ of girls would like to talk to their parents more often about their future. This means that respondents feel the need to discuss with their parents plans for the future, perhaps they expect their help in planning and/or supporting the choice already made. In the group of young men this need is expressed more strongly. Almost half of the respondents would prefer to talk to their parents about "different things," that is, they want to expand the list of topics, but they can not specify them. This may be an indirect sign of problems in the relationship between parents and children.

According to respondents, the initiator of communication is mostly the mother, in second place the respondent himself, and the father - in third place. It is important to note that none of the interviewed girls and only $13 \%$ of the young men indicated that the initiator of the conversation was the father. Almost half of the young men and $87 \%$ of the girls noted that during the conversation with the mother they were in equal positions with a parent. Only $40 \%$ of responders communicate as equal partners with the father. The fact that they talk more with their father, noted $24 \%$ of boys and $13 \%$ of girls. They answered that $13 \%$ of young men and $20 \%$ of girls themselves speak more.

As for the feelings that young men and women experience during a conversation with their parents, half of the interviewed boys and $80 \%$ of the girls experience positive emotions while communicating with their parents. Also, $77 \%$ of girls and $53 \%$ of young men believe that their parents understand them. The rest of the respondents do not share the same feeling.

During the conversation negative emotions are experienced more often by young men (15\%), and only by $7 \%$ of women. $36 \%$ of boys and $13 \%$ of girls answered that they do not feel anything. Apparently for those respondents, communication with parents is formal and emotionally they are not included in the conversation.

As for the feelings experienced by the respondents after communicating with their parents, most of the young men and women are in a good mood. Talking to parents helps $85 \%$ of respondents to understand their difficulties. At the same time, $40 \%$ of young men and $27 \%$ of girls celebrate a feeling of understanding after talking with their parents. At the same time, $86 \%$ of girls and $80 \%$ of boys try to be sincere in communicating with their parents. However, $20 \%$ of young men said that it is difficult for them to be sincere.

Thus, the survey showed that only one third of respondents are satisfied with the amount of time they spend with their parents. Moreover, more than half of the boys and a third of girls communicate with their parents no more than an hour a day. Respondents are more likely to communicate with their mother, and not with their father. Father rarely acts as the initiator of communication. The usual topics for conversation are study, hobbies, love, everyday issues. Young people would like to discuss their future with parents more often.

Based on the analysis of the results, we can conclude that the formal content of the communication of girls and boys with their parents is both general and different.

1. Every fifth subject irrespective of sex is dominated by the indifferent orientation of the person in communication, and they try to avoid it. For each third, the meaning of communication is the manipulation of the other. Each fourth demonstrates an altrocentric orientation and promotes the development of a partner to the detriment of himself. These three types of communication focus dominate both boys and girls.

2. As for the differences, young males are more expressive of the authoritarian form of the person's orientation in communication. Girls often display a refusal of equality in communication in favor of the interlocutor, which means a conformal orientation in communication. Dialogic orientation in communication is the least expressed in both groups, while in girls it is less expressed than in young men.

3. Regardless of gender, only one third of respondents communicate with their parents for more than three hours, communicate more often with their mother and take an equal position. The common theme of the conversation is study. Most people experience positive emotions during the conversation, try to be sincere. At the same time, every fifth respondent finds it difficult to name specific topics that they are discussing.

4. Boys are less likely to need communication with their parents. Twice more often than girls experience negative emotions in communication and a feeling of understatement after talking with their parents. At the same time they have a stronger need to discuss their future with their parents. It is more difficult for them to be sincere when communicating with their parents. Girls often turn to their parents for advice and share their secrets with them. They usually discuss such topics with their parents as love and life. A special theme of the conversation with the parents of the young men is the work of parents and hobbies.

\section{References}

1. M.M. Buhtin, Aesthetics of verbal work (Art, Moscow, 1979) 
2. T.A. Topolskaya, Consultative psychology and psychotherapy 4, 69-90 (2011)

3. R. Hykner, L. Jkobs. The healing relations. Dialoggestalt approach, (Gestalt journal press, San-Diego, 1995)

4. A.F.Kopyev, Consultative psychology and psychotherapy 1, 83-102 (2010)

5. Yu.S. Pezhemskaya, Psychology of Education in the 21st Century: Theory and Practice, 143-148, (2011)

6. S.M. Morozov, Consultative psychology and psychotherapy 2, 34-51 (2011)

7. L.I. Vorobyova, Moscow Therapeutic Journal 2, 528 (2006)

8. R.L. Kalimzhanova, Preventing Addictions 1, 21-27 (2017)

9. A.B. Kholmogorova, E.N. Klimenkova, Psychological science and education 8(4), 129-141 (2016)

10. L.M. Carrier at al. Computers in Human Behavior, 39-48 (2015)

11. A.Yu. Ivanova, M.V. Malyshkina, Uchenye zapiski universiteta imeni P.F. Lesgaft 7, 221-228 (2017)

12. I.S. Kon, Child and society (Academy, Moscow, 2003)

13. J.J. Arnett, The cultural psychology of a new life stage, Bridging cultural and developmental approaches to psychology: New synthesis in theory, research, and policy, 255-275 (2011)

14. H.H. Tolstykh, Consultative psychology and psychotherapy 4, 7-24 (2015)

15. S.L. Bratchenko, Existential psychology of deep communication, (Sense, Moscow, 2001) 